Original Research

\title{
UJI AKTIVITAS ANTIBAKTERI FRAKSI N-HEKSAN, ETIL ASETAT, DAN BUTANOL DAUN PETAI CINA (Leucaena leucocephala (Lam.) de Wit) TERHADAP BAKTERI Propionibacterium acnes DAN Staphylococcus epidermidis SECARA IN VITRO
}

\section{ANTIBACTERIAL ACTIVITY OF N-HEXANE, ETHYL ACETATE, AND BUTANOL FRACTION OF LEAD TREE (Leucaena leucocephala (Lam.) de Wit) LEAVES AGAINST Propionibacterium acnes AND Staphylococcus epidermidis}

\author{
Dessy Tumiar Pakpahan ${ }^{1}$, *Sutriningsih ${ }^{2}$ \\ 1,2 Fakultas Farmasi, Universitas 17 Agustus 1945, Jakarta, Indonesia, 14350 \\ *E-mail : vinnelaras@yahoo.co.id
}

Diterima: $17 / 09 / 19$

Direvisi: 08/11/19

Disetujui: 02/11/19

\begin{abstract}
Abstrak
Jerawat merupakan penyakit kulit yang biasa muncul pada wajah, leher, dada dan punggung. Jerawat disebabkan oleh aktivitas kelenjar minyak yang berlebihan dan diperburuk oleh infeksi bakteri. Petai cina (Leucaena leucocephala (Lam.) de Wit.) merupakan sejenis tanaman perdu yang banyak tumbuh dan dikembangkan di Indonesia. Pada daun petai cina ditemukan keberadaan banyak kandungan senyawa metabolit sekunder dan dipercaya dapat digunakan sebagai obat antijerawat. Senyawa metabolit sekunder dapat bersifat nonpolar, semipolar, dan polar sehingga untuk memaksimalkan pengekstrakan senyawa metabolit sekunder dilakukan partisi dengan berbagai variasi pelarut (fraksinasi). Proses fraksinasi dalam penelitian ini menggunakan pelarut $n$-heksan, etil asetat, dan butanol, sedangkan bakteri uji yang digunakan adalah bakteri Propionibacterium acnes dan Staphylococcus epidermidis. Pengujian aktivitas antibakteri dilakukan dengan metode difusi agar. Uji aktivitas antibakteri menunjukkan bahwa fraksi n-heksan, etil asetat dan butanol daun petai cina mampu menghambat pertumbuhan bakteri Propionibacterium acnes dan Staphylococcus epidermidis. Hasil uji aktivitas antibakteri menunjukkan fraksi paling aktif adalah fraksi etil asetat. Aktivitas antibakteri fraksi etil asetat terbaik pada bakteri Propionibacterium acnes diperoleh pada konsentrasi $200 \mathrm{mg} / \mathrm{mL}$ dengan rata-rata diameter zona hambat sebesar $12,22 \mathrm{~mm}$, sedangkan pada bakteri Staphylococcus epidermidis sebesar 16,41 mm.
\end{abstract}

Kata kunci: Daun petai cina (Leucaena leucocephala (Lam.) de Wit); Acne; Fraksinasi; Antibakteri; Disc Diffusion

\begin{abstract}
Acne is a skin disease that usually appears on the face, neck, chest and back. Acne is caused by excessive oil gland activity and is made worse by bacterial infections. Petai Cina (Leucaena leucocephala (Lam.) de Wit) is a type of shrub that grows and develops in Indonesia. In the Petai Cina leaves have been found the presence of many secondary metabolite compounds and is believed to be used as an anti-acne. Secondary metabolites can be nonpolar, semipolar, and polar, so as to maximize the extraction of secondary metabolites is determined by partitioning with a variety of solvents (fraction). The fraction process was done by using n-hexane, ethyl acetate, and butanol, while the bacteria used were Propionibacterium acnes and Staphylococcus epidermidis. The antibacterial activity test was determined by agar diffusion method. The antibacterial activity test showed that the fraction of n-hexane, ethyl acetate and butanol of Petai Cina leaves were able to inhibit the growth of Propionibacterium acnes and Staphylococcus epidermidis. The most active fraction was the ethyl acetate fraction. The best antibacterial activity of ethyl acetate fraction against Propionibacterium acnes was obtained at a concentration of $200 \mathrm{mg} / \mathrm{mL}$ with an average inhibition zone $12.22 \mathrm{~mm}$, and Staphylococcus epidermidis with an average inhibition zone $16.41 \mathrm{~mm}$.
\end{abstract}


Keywords : Petai Cina leaves (Leucaena leucocephala (Lam.) de Wit); Acne; Fractionation; Antibacterial; Disc Diffusion.

\section{PENDAHULUAN}

Jerawat merupakan penyakit kulit yang dikenal dengan sebutan acne vulgaris dan hampir semua orang pernah mengalaminya. Jerawat biasa terjadi pada remaja dan dewasa muda, yaitu pada usia 14-17 tahun pada wanita dan 16-19 tahun pada pria. Jerawat akan hilang pada usia sekitaran 20-30 tahun. Namun terkadang jerawat dapat menetap sampai dekade umur 30 tahun lebih [1].

Jerawat biasanya timbul pada wajah, leher, dada, punggung bagian atas, dan lengan. Bagian-bagian tersebut adalah bagian yang paling sering ditumbuhi jerawat karena pada bagian tersebut banyak memproduksi minyak [2].

Jerawat muncul pada saat kelenjar minyak kulit terlalu aktif, sehingga pori-pori kulit akan tersumbat oleh timbunan lemak yang berlebihan. Jika timbunan itu bercampur dengan keringat, debu dan kotoran lain, maka akan menyebabkan timbunan lemak dengan bintik hitam di atasnya yang disebut komedo. Jika pada komedo itu terdapat infeksi bakteri, maka terjadilah peradangan yang dikenal dengan jerawat yang ukurannya bervariasi mulai dari ukuran kecil sampai ukuran besar serta berwarna merah, kadang-kadang bernanah serta menimbulkan rasa nyeri [3].

Bakteri yang paling umum menginfeksi jerawat adalah Propionibacterium acnes, Staphylococcus epidermidis, dan Stapylococcus aureus. Bakteri ini tidak patogen pada kondisi kulit normal, tetapi jika terjadi perubahan kondisi kulit yang menimbulkan penyumbatan oleh minyak, maka bakteri tersebut akan menjadi invasif dan menyebabkan peradangan [4].

Salah satu tanaman yang dapat dimanfaatkan sebagai obat tradisional untuk antijerawat adalah tanaman petai cina (Leucaena leucocephala (Lam.) De Wit.). Secara etnobotani masyarakat Indonesia telah memanfaatkan daun petai cina sebagai obat-obatan diantaranya sebagai obat luka dan bengkak.

Pada penelitian terdahulu diketahui bahwa ekstrak etanol daun petai cina terbukti mempunyai aktivitas antibakteri terhadap Staphylococcus epidermidis [5] dan Staphylococcus aureus [6]. Penelitian antibakteri pada fraksi daun petai cina belum banyak dilakukan, oleh karena itu dinilai penting untuk melakukan penelitian lebih lanjut terhadap fraksi senyawa daun petai cina yang memiliki aktivitas antibakteri paling baik.

\section{METODE}

Bahan

Daun petai cina, aquadest (Brataco), etanol 70\% (Brataco), n-heksan (Merck, Damstardt, Germany) dan etil asetat (Merck, Damstardt, Germany), butanol (Merck, Damstardt, Germany), media Mueller Hinton Agar, media Nutrient Agar, dan darah domba steril. 


\section{PROSEDUR KERJA}

\section{Pembuatan Ekstrak}

Daun petai cina yang segar dicuci dan dibersihkan dari pengotornya, kemudian dikeringkan dengan cara diangin-anginkan. Setelah kering, simplisia digiling dan diayak dengan pengayak ukuran 40 mesh hingga menjadi serbuk. Selanjutnya serbuk simplisia diekstraksi dengan metode maserasi menggunakan etanol 70\% selama 3x24 jam, diaduk dan dibiarkan dalam bejana tertutup, kemudian disaring dan diambil filtratnya. Selanjutnya filtratnya dipekatkan dengan menggunakan rotary vaccum evaporator hingga diperoleh ekstrak kental.

\section{Fraksinasi}

Pemisahan ekstrak etanol kental daun petai cina dilakukan dengan metode ECC (Ekstraksi Cair-Cair). Fraksinasi dilakukan sebagai berikut: 30 gram ekstrak etanol $70 \%$ daun petai cina dilarutkan dalam aqua destilata sebanyak $90 \mathrm{~mL}$ dimasukkan kedalam corong pisah, ditambahkan $90 \mathrm{~mL}$ pelarut n-heksan, dikocok secara perlahan-lahan, lalu didiamkan hingga terjadi pemisahan antara fraksi n-heksan dan aqua destilata. Fraksi n-heksan dipisahkan, kemudian diulangi beberapa kali penyarian sampai larutan berwarna bening. Fraksinasi dilanjutkan menggunakan pelarut etil asetat dan butanol dengan proses yang sama dengan partisi n-heksan. Fraksi n-heksan cair, fraksi etil asetat cair dan fraksi butanol cair diuapkan dengan alat rotary evaporator sehingga diperoleh fraksi kental.

\section{Uji Aktivitas Antibakteri}

Uji aktivitas dilakukan terhadap bakteri Propionibacterium acnes dan Staphylococcus epidermidis menggunakan metode difusi agar. Sebanyak $100 \mu \mathrm{L}$ suspense bakteri Propionibacterium acnes dimasukkan ke atas permukaan media agar darah dan suspensi bakteri Staphylococcus epidermidis ke atas permukaan media MHA (Mueller Hinton Agar), kemudian diratakan dengan batang L. Hasil fraksi n-heksan, etil asetat, dan butanol daun petai cina dibuat dalam berbagai konsentrasi $(200,100,50,25$, dan $12,5 \mathrm{mg} / \mathrm{mL})$. Diambil $10 \mu \mathrm{L}$ dari masingmasing konsentrasi dimasukkan kedalam disk kosong, serta kontrol positif (klindamisin $2 \mu$ ) dan kontrol negatif (DMSO 10\%) diletakkan keatas permukaan media uji, kemudian diinkubasi pada suhu $37^{\circ} \mathrm{C}$ selama 18-24 jam untuk bakteri Staphylococcus epidermidis dan selama 48 jam untuk bakteri Propionibacterium acnes. Setelah itu diukur diameter daerah hambat menggunakan jangka sorong. Pengujian ini dilakukan sebanyak tiga kali.

\section{HASIL DAN PEMBAHASAN}

\section{Ekstraksi Daun Petai Cina}

Pembuatan ekstak daun petai cina dilakukan dengan metode maserasi dengan pelarut etanol 70\%. Etanol dipertimbangkan sebagai penyari karena etanol dapat menarik senyawasenyawa yang bersifat polar dan nonpolar, selain itu etanol tidak beracun, aman digunakan, serta jamur, bakteri, ataupun parasit sulit tumbuh didalamnya. Berat ekstrak kental yang didapatkan dari $1 \mathrm{~kg}$ simplisia adalah 82,7 gram dengan rendemen sebesar 8,27\%. 

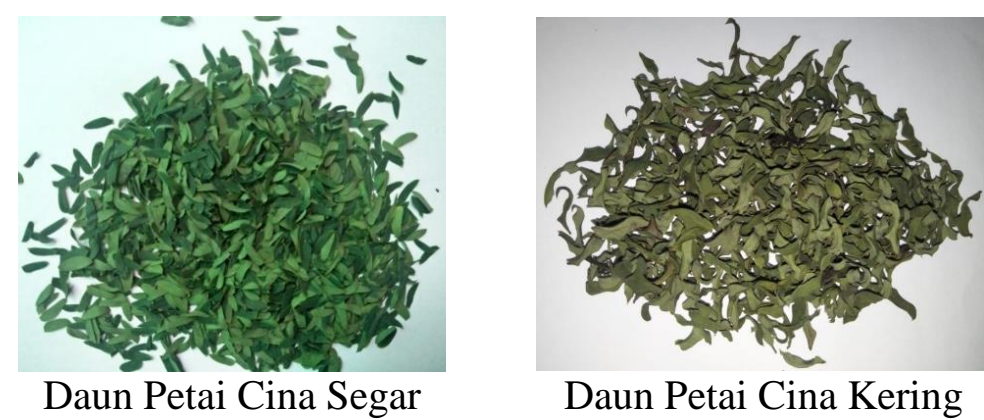

\section{Fraksinasi Daun Petai Cina}

Metabolit sekunder dapat bersifat nonpolar, semipolar, dan polar, sehingga untuk memaksimalkan pengekstrakan senyawa metabolit sekunder dilakukan partisi dengan berbagai variasi pelarut (fraksinasi). Pemisahan secara partisi cair-cair harus memiliki perbedaan kelarutan antara pelarut dan zat terlarut serta kedua pelarut yang digunakan tidak saling bercampur. Proses fraksinasi menggunakan pelarut n-heksan (nonpolar), etil asetat (semipolar), dan butanol (polar). Masing-masing pelarut akan melarutkan senyawa metabolit sekunder yang memiliki kepolaran yang sama. Berat fraksi kental yang didapatkan dari 30 gram ekstrak etanol $70 \%$ daun petai cina adalah fraksi n-heksan sebesar $1,72 \mathrm{~g}$ dengan rendemen $5,73 \%$, fraksi etil asetat sebesar 3,26 g dengan rendemen 12,47\%, dan fraksi butanol sebesar 3,26 g dengan rendemen $10,87 \%$.

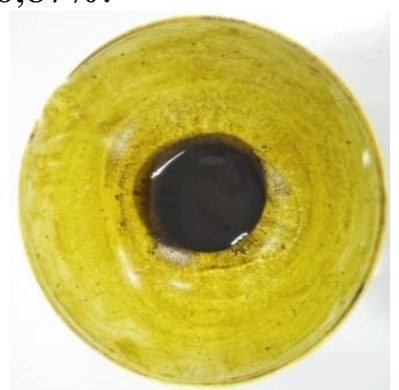

Hasil fraksi n-heksan

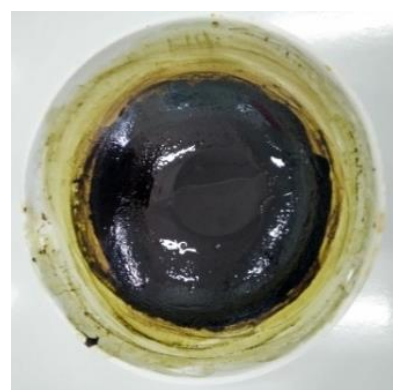

Hasil fraksi etil asetat

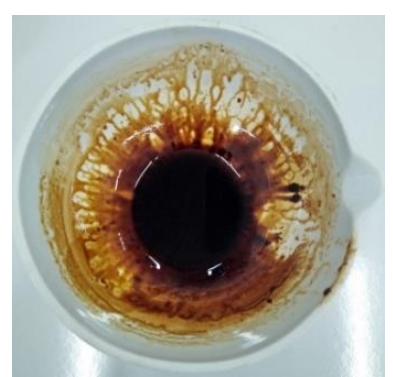

Hasil fraksi butanol

\section{Skrining Fitokimia}

Penapisan fitokimia bertujuan untuk mengetahui keberadaan golongan senyawa metabolit sekunder yang ada dalam ekstrak. Hasil penapisan fitokimia dapat dilihat pada Tabel 1.

Tabel 1. Hasil penapisan fitokimia

\begin{tabular}{|l|c|c|c|c|}
\hline \multirow{2}{*}{ Uji Fitokimia } & \multicolumn{4}{|c|}{ Hasil Pengujian } \\
\cline { 2 - 5 } & $\begin{array}{c}\text { Ekstrak } \\
\text { Etanol }\end{array}$ & $\begin{array}{c}\text { Fraksi } \\
\text { n-Heksan }\end{array}$ & $\begin{array}{c}\text { Fraksi } \\
\text { Etil Asetat }\end{array}$ & $\begin{array}{c}\text { Fraksi } \\
\text { Butanol }\end{array}$ \\
\hline Alkaloid & + & + & + & + \\
\hline Saponin & + & + & + & + \\
\hline Tanin & + & + & + & + \\
\hline Fenolik & + & + & + & + \\
\hline Flavonoid & + & - & + & + \\
\hline Triterpenoid & + & + & - & - \\
\hline Steroid & - & - & - & - \\
\hline
\end{tabular}




\section{Uji Aktivitas Antibakteri}

Uji aktivitas antibakteri dalam penelitian ini menggunakan metode difusi cakram yaitu hasil daya uji antibakteri didasarkan pada pengukuran diameter zona hambat pertumbuhan bakteri yang terbentuk disekeliling kertas cakram. Bakteri uji yang digunakan dalam penelitian ini adalah Propionibacterium acnes dan Staphylococcus epidermidis. Hasil pengujian aktivitas antibakteri dapat dilihat pada Tabel 3 dan Tabel 4.

Tabel 2. Hasil pengujian aktivitas antibakteri fraksi n-heksan, etil asetat dan butanol daun petai cina terhadap bakteri Staphylococcus epidermidis.

\begin{tabular}{|c|c|c|c|c|c|}
\hline \multirow{2}{*}{ Fraksi Uji } & \multirow{2}{*}{$\begin{array}{c}\text { Konsentrasi } \\
(\mathrm{mg} / \mathrm{mL})\end{array}$} & \multicolumn{3}{|c|}{ Diameter Daya Hambat (mm) } & \multirow{2}{*}{$\begin{array}{c}\text { Rata-rata } \\
\text { diameter }(\mathrm{mm})\end{array}$} \\
\hline & & $\mathrm{I}$ & II & III & \\
\hline \multirow{7}{*}{ n-Heksan } & 200 & 12,29 & 13,48 & 10,11 & 11,96 \\
\hline & 100 & 10,22 & 12,05 & 9,49 & 10,58 \\
\hline & 50 & 9,94 & 10,59 & 7,36 & 9,29 \\
\hline & 25 & 7,11 & 7,44 & 6,89 & 7,14 \\
\hline & 12.5 & 6 & 6,97 & 6 & 6,32 \\
\hline & KKP & 15,22 & 14,42 & 15,39 & 15,01 \\
\hline & $\mathrm{KKN}$ & 6 & 6 & 6 & 6 \\
\hline \multirow{7}{*}{ Etil Asetat } & 200 & 18,76 & 16,29 & 14,19 & 16,41 \\
\hline & 100 & 13,37 & 11,8 & 11,72 & 12,29 \\
\hline & 50 & 12,14 & 10,87 & 9,41 & 10,8 \\
\hline & 25 & 10,52 & 9,14 & 8,32 & 9,32 \\
\hline & 12.5 & 9,82 & 8,17 & 7,36 & 8,45 \\
\hline & KKP & 16,05 & 15,98 & 15,34 & 15,79 \\
\hline & KKN & 6 & 6 & 6 & 6 \\
\hline \multirow{7}{*}{ Butanol } & 200 & 8,08 & 9,39 & 9,28 & 8,91 \\
\hline & 100 & 7,47 & 8,14 & 7,18 & 7,59 \\
\hline & 50 & 6,9 & 7,68 & 6,75 & 7,11 \\
\hline & 25 & 6 & 6,84 & 6 & 6,28 \\
\hline & 12.5 & 6 & 6 & 6 & 6 \\
\hline & KKP & 15,58 & 14,38 & 16,61 & 15,52 \\
\hline & $\mathrm{KKN}$ & 6 & 6 & 6 & 6 \\
\hline
\end{tabular}

Keterangan ;

KKP (Kelompok Kontrol Positif) : Klindamisin disk $(2 \mu \mathrm{g})$

KKN (Kelompok Kontrol Negatif) : DMSO 10\% 
Tabel 3. Hasil pengujian aktivitas antibakteri fraksi n-heksan, fraksi etil asetat dan fraksi butanol daun petai cina terhadap bakteri Propionibacterium acnes.

\begin{tabular}{|c|c|c|c|c|c|}
\hline \multirow{2}{*}{ Fraksi Uji } & \multirow{2}{*}{$\begin{array}{c}\text { Konsentrasi } \\
(\mathrm{mg} / \mathrm{mL})\end{array}$} & \multicolumn{3}{|c|}{ Diameter Daya Hambat (mm) } & \multirow{2}{*}{$\begin{array}{c}\text { Rata-rata } \\
\text { diameter }(\mathrm{mm})\end{array}$} \\
\hline & & $\mathrm{I}$ & II & III & \\
\hline \multirow{7}{*}{ n-Heksan } & 200 & 9,14 & 9,32 & 11,58 & 10,01 \\
\hline & 100 & 8,37 & 8,93 & 7,56 & 8,28 \\
\hline & 50 & 6,93 & 6 & 6 & 6,31 \\
\hline & 25 & 6 & 6 & 6 & 6 \\
\hline & 12.5 & 6 & 6 & 6 & 6 \\
\hline & KKP & 14,78 & 13,45 & 14,03 & 14,08 \\
\hline & KKN & 6 & 6 & 6 & 6 \\
\hline \multirow{7}{*}{ Etil Asetat } & 200 & 12,18 & 12,89 & 11,55 & 12,2 \\
\hline & 100 & 11,52 & 10,78 & 10,46 & 10,92 \\
\hline & 50 & 9,88 & 7,42 & 8,34 & 8,54 \\
\hline & 25 & 6 & 6 & 6 & 6 \\
\hline & 12.5 & 6 & 6 & 6 & 6 \\
\hline & KKP & 14,77 & 13,48 & 13,95 & 14,06 \\
\hline & KKN & 6 & 6 & 6 & 6 \\
\hline \multirow{7}{*}{ Butanol } & 200 & 8,09 & 8,48 & 9,64 & 8,73 \\
\hline & 100 & 6,7 & 6,34 & 7,29 & 6,77 \\
\hline & 50 & 6 & 6 & 6 & 6 \\
\hline & 25 & 6 & 6 & 6 & 6 \\
\hline & 12.5 & 6 & 6 & 6 & 6 \\
\hline & KKP & 14,96 & 13,91 & 14,63 & 14,50 \\
\hline & KKN & 6 & 6 & 6 & 6 \\
\hline
\end{tabular}

Keterangan ;

KKP (Kelompok Kontrol Positif) : Klindamisin disk $(2 \mu \mathrm{g})$

KKN (Kelompok Kontrol Negatif) : DMSO 10\%

Konsentrasi efektif suatu zat aktif yang nantinya dapat menjadi tolak ukur dalam mengambil nilai minimum untuk uji antibakteri bila diameter zona hambatnya $>10 \mathrm{~mm}$ [7].

Fraksi yang paling aktif sebagai antibakteri dalam menghambat bakteri Propionibacterium acnes dan Staphylococcus epidermidis adalah fraksi etil asetat. Fraksi etil asetat daun petai cina yang efektif dalam menghambat pertumbuhan bakteri Propionibacterium acnes dan Staphylococcus epidermidis terdapat pada konsentrasi $200 \mathrm{mg} / \mathrm{mL}$ dan $100 \mathrm{mg} / \mathrm{mL}$.

Fraksi n-heksan daun petai cina juga mempunyai aktivitas antibakteri terhadap pertumbuhan bakteri Staphylococcus epidermidis dan Propionibacterium acnes meskipun diameter zona hambat yang dihasilkan tidak lebih besar dari fraksi etil asetat. Fraksi n-heksan daun petai cina efektif dalam menghambat pertumbuhan bakteri Staphyloccus epidermidis pada konsentrasi 200 $\mathrm{mg} / \mathrm{mL}$ dan $100 \mathrm{mg} / \mathrm{mL}$, sedangkan fraksi n-heksan daun petai cina hanya efektif pada konsentrasi $200 \mathrm{mg} / \mathrm{mL}$ dalam menghambat pertumbuhan bakteri Propionibacterium acnes. 
Fraksi butanol daun petai cina mempunyai aktivitas antibakteri yang paling rendah dibandingkan dengan fraksi etil asetat dan fraksi n-heksan. Hal ini diduga karena senyawa kimia yang tertarik dalam fraksi butanol yang sangat rendah. Fraksi butanol daun petai cina tidak efektif sebagai antibakteri terhadap pertumbuhan bakteri Staphyloccocus epidermidis dan Propionibacterium acnes karena tolak ukur dalam mengambil nilai minimum untuk uji antibakteri bila diameter zona hambatnya $>10 \mathrm{~mm}$, sehingga perlu dilakukan uji lebih lanjut untuk mengetahui pada konsentrasi berapa fraksi butanol efektif dapat menghambat pertumbuhan bakteri Staphyloccocus epidermidis dan Propionibacterium acnes.

Hasil uji two way anova didapat nilai signifikansi $<0,05$ sehingga dapat dikatakan terdapat perbedaan nilai daya hambat yang signifikan secara statistik. Berdasarkan hasil uji terhadap kelompok perlakuan diperoleh nilai sig 0,000 dimana artinya pengaruh kelompok perlakuan terhadap daya hambat bakteri signifikan, lalu pada bakteri diperoleh nilai sig 0,000 yang artinya pengaruh kelompok bakteri mempengaruhi daya hambat secara signifikan. Artinya ada perbedaan daya hambat terhadap bakteri Staphylococcus epidermidis dengan Propionibacterium acne. Pengujian kemudian dilanjutkan menggunakan uji post hoc Least significant Difference (LSD) untuk menentukan kelompok perlakuan mana yang memiliki perbedaan. Dari hasil post hoc dapat disimpulkan bahwa etil asetat $200 \mathrm{mg} / \mathrm{mL}$ tidak memiliki perbedaan yang signifikan terhadap kelompok kontrol positif. Hal ini berarti bahwa kedua kelompok perlakuan tersebut memberikan daya hambat yang sama dengan kelompok kontrol positif. Sedangkan kelompok perlakuan lainnya memiliki perbedaan yang signifikan dengan kontrol positif dan memberikan daya hambat yang berbeda secara statistik dengan kelompok kontrol positif.

\section{KESIMPULAN}

Fraksi n-heksan, etil asetat, dan butanol daun petai cina (Leucaena leucocephala (Lam.) de Wit) memiliki sifat antibakteri terhadap pertumbuhan bakteri Propionibacterium acnes dan Staphylococcus epidermidis. Fraksi yang paling aktif dalam menghambat pertumbuhan bakteri Propionibacterium acnes dan Staphylococcus epidermidis adalah etil asetat pada konsentrasi 200mg/mL dengan rata-rata diameter daya hambat terhadap bakteri Propionibacterium acnes sebesar 12,20 mm dan terhadap bakteri Staphylococcus epidermidis sebesar 16,41 mm.

\section{DAFTAR PUSTAKA}

1. Brooks, G., Carroll, K. C., Butel, J. \& Morse, S. Mikrobiologi Kedokteran Jawetz, Melnick \& Adelberg's. Jakarta. 2008, 627-9.

2. Santoso, Hyeronimus Budi. Tampil Cantik Tanpa Jerawat. Yogyakarta. Victoria Press. 2010

3. Djajadisastra, J., Dessy, N. P. Formulasi Gel Topikal dari Ekstrak Nerii Folium dalam Sediaan Anti Jerawat. Jurnal Farmasi Indonesia. 2010,4: 210-216.

4. Radji, M,. Buku Ajar Mikrobiologi Panduan Mahasiswa Farmasi dan Kedokteran. Jakarta. 2010.

5. Suryana, S., Yen, Y., Nuraeni, A., Rostinawati, T., Farmasi, F., Padjadjaran, U., \& Barat, J. Aktivitas Antibakteri Ekstrak Etanol Dari Lima Tanaman Terhadap Bakteri Staphylococcus Epidermidis Dengan Metode Mikrodilusi M7. 2017:4, 2-10. 
6. Retnaningsih. Uji Daya Hambat Daun Petai Cina (Leucaena Leucocephala Folium) Terhadap Bakteri Staphylococcus Aureus Dan Escherichia Coli Menggunakan Metode Difusi Agar. Jurnal Dunia Kesmas. 2016.

7. Purwanto, Sigit. Uji Aktivitas Antibakteri Fraksi Aktif Ekstrak Daun Senggani. Jurnal Keperawatan Sriwijaya. 2015; 2(2355), 84-92. 